\title{
Tin Hat Games - Producing, Funding, and Consuming an Independent Role-Playing Game in the Age of the Interactive Spectacle
}

\author{
Chiara Bassetti, Maurizio Teli, Annalisa Murgia
}

\section{Premise: The Age of the Interactive Spectacle}

In The Society of the Spectacle, Guy Debord (1967/1994) describes a society in which the human capabilities of being and having have been subsumed by representation, as the main trait of the society of the 1970s from which Debord was writing. Practically, Debord was referring to information and propaganda, advertising, and leisure consumption as the main forms through which the spectacle, the domain of representation, manifests itself as the dominant model for social life (Thesis 6). With such a reference, Debord was stressing how the spectacle is separate from the reality of life, and wraps it with representation. Nevertheless, the relation of separation between the reality of life and the representation of the spectacle is a dialectic one, with 'reality

How to cite this book chapter:

Bassetti, C., Teli, M. and Murgia, A. 2017. Tin Hat Games - Producing, Funding, and Consuming an Independent Role-Playing Game in the Age of the Interactive Spectacle. In: Briziarelli, M. and Armano, E. (eds.). The Spectacle 2.0: Reading Debord in the Context of Digital Capitalism. Pp. 167-182. London: University of Westminster Press. DOI: https://doi.org/10.16997/book11.j. License: CC-BYNC-ND 4.0 
emerging in the spectacle and the spectacle being real' (Thesis 8 ). The spectacle is therefore a specific historical moment (Thesis 11), the main production of society (Thesis 15). Any social reality is represented, and it appears only outside of itself (Thesis 17). The spectacle, in all its practical forms, is a selfreflective monologue of the existing order, essentially unilateral communication organised to preserve the role of the current ruling class (Thesis 24). In Debord's view, even the world of 'culture' and the academic disciplines that define themselves as 'critical', like sociology, are part of such a monologue, as they detach their theoretical discourse from the reality of lived experience (Theses 180, 196, and 197).

Under these assumptions, only by recognizing the centrality of the spectacle, the reality of representations, and the necessity of combining theory with the experience of life, it is possible to organise forms of resistance. Resistance to the prevalence of the spectacle then takes the form of the détournement, the dialectical inversion of the existing relations among concepts, applied also to the existing forms of critique (Thesis 206). Debord concludes by underlining how through the détournement, it is possible to create a critique of the existing culture, the separated one produced by the spectacle, without detaching it from the critique of the existing social relations. In this way, critique reaches a new dialectical unity, by bringing together what the spectacle is separating: culture and social relations (Thesis 210).

Debord's analysis was historically situated in the 1970s and it dealt with a world of spectacle based on centralized modes of production of cultural objects, symbolised by broadcasting media like cinema, radio, or television. At the end of the '90s, Best and Kellner (1999) interrogated Debord in light of the emerging electronic media, like 'the computer, multimedia, and virtual reality devices' (10). Best and Kellner stressed how such media were anticipating a new stage of the spectacle, the 'interactive spectacle' (ibidem: 9). What differentiates the stage of the interactive spectacle is the relationship between the objects of the spectacle and the subjects of everyday life. If, in Debord's age, the spectator was almost a passive consumer of broadcasted cultural products, in the interactive spectacle, the subject appears as having a wider capability of action. Best and Kellner do not indulge in a naive celebration of interactivity, however. Rather, they foresee how the technical means of production of the spectacle, the interactive media technologies like protocols of computer programs, gain a central role in shaping social relations and the production of the spectacle itself. Indeed, in the Spectacle 2.0, which this book takes as a heuristic tool to understand current capitalist societies, human social lives are both the mediated objects and the mediating subjects (Armano and Briziarelli, this volume) of representation. Emerging from the self-spectacularization played on the discursive and interactive terrain of social media and other ICTs, subjectivities are the products themselves of the spectacle (ivi). The present essay is an investigation into the age of the interactive spectacle. 


\section{Producing Counternarratives Today: A Theoretical Reading of Tin Hat Games}

The empirical case we discuss in this essay is Tin Hat Games, a small association of independent game designers, producers and promoters. Such an empirical field lies at the crossroads of a multifaceted set of contemporary social phenomena, such as gamification, the role of social critique, platform capitalism, and highly skilled free work - it therefore enlightens their multiple interrelations. Such interrelations take place in the context of the creative industries, one of the loci of production of the spectacle, even in the traditional sense. Moreover, creative industries are the emblem of the ways to relate to the forms of work (Armano and Murgia 2015) that express the 'spirit' of the current capitalist model (Boltanski and Chiapello 1999).

It is a capitalist model characterized also (but not only) by forms of gamification, in which the passions of people are put at play through mechanisms derived from gaming, to increase their productivity, thereby mixing the fun experience of gaming with the goal of maximising production (Jagoda 2013). Indeed, this is another form of a model of dispossession, in which economic value gets extracted from people's life (Harvey 2014). The case of Tin Hat shows how human passions, technological arrangements, and the organization of production are tied together in the contemporary production of the spectacle, in our case a cultural product like a role-playing game, called \#UrbanHeroes (\#UH).

First and foremost, \#UrbanHeroes is a case of countergaming, a way to embed critique of the social landscape and the game industry in the game itself (Galloway 2006). Such countergaming takes place in a social context in which, through what is referred to as gamification, game mechanics and principles are exported to other social domains, often with the declared goal of achieving a boost in productivity or in customer satisfaction (Jagoda 2013). The existence of \#UrbanHeroes per se, as a form of social critique embedded in a contemporary world of superheroes, can be read indeed as counteracting gamification at a deep level, not by bringing games to other social domains but by bringing social life into the game. Speaking a Debordian language, Tin Hat Games and countergaming practices are dialectically opposing the gamification of life.

Nevertheless, as Jagoda (ibidem) highlighted, complicities of countergaming with gamified capitalism are practically unavoidable, and the case of Tin Hat shows that clearly. For example, the counter-action of Tin Hat, including the successful production and distribution of \#UrbanHeroes, would not have been possible today without recourse to digital platforms like Facebook and Kickstarter, which are part of contemporary platform capitalism (Scholz 2016; Srnicek 2016; ; Armano, Murgia and Teli 2017). Indeed, contemporary digital platforms act as organizers of forms of social cooperation out of which economic value is algorithmically extracted (van Dijck 2013). In this way, the case of Tin Hat allows for an empirical investigation of the practicalities of the 
centrality of (new) media, (unpaid) digital labour, and specific aesthetics in the age of the interactive spectacle.

Moreover, the work of Tin Hat members is non-paid work. Indeed, even if the association is financially healthy - which means that the members can cover almost all the expenses with precedent revenues -Tin Hat is not a source of income for them. To this extent, Tin Hat activities appear as a form of 'free work', and another case of the dialectic between passion and work that characterizes contemporary forms of production (Ballatore, Del Rio Carral and Murgia 2014). The association is composed of friends who share the same passion and who would probably run the association even if they were unemployed, The activities are carried out outside the paid work and during their 'free time' showing how forms of collaboration based on shared values (Hearn 2010; Arvidsson and Pietersen 2013) might intertwine with forms of exploitation of platform capitalism (Fuchs 2014). In other words, Tin Hat activities combine countergaming with a work that is 'free' in the double sense of being done autonomously and with a high level of passionate commitment, but not paid and/or not providing an income to the members of the association (Beverungen et al. 2013; Chicchi et al. 2014). Thus, Tin Hat members merge a critique of the world of gaming, through their internal work practices, with a critique of society at large, through their products. Yet they are producers of the spectacle, which leaves room for counternarratives, but being still based, at least partially, on neoliberal modes of production.

The case of Tin Hat allows us to show, at the level of a specific, small scale project, how the subjective elements related to biographical experiences and perceived desires constantly intermingle with technological elements and platform capitalism, and these elements contribute to renewed spectacular products, thereby enlightening the functioning of the interactive spectacle.

\section{The Case Study}

Officially funded in 2014, yet at work on its initial project - \#UrbanHeroes since almost two years earlier, Tin Hat is composed of three members: Alex, Matt, and Manuel. Alex is the game creator who started working on the idea when he was 18 years old. He is now 32 and, having withdrawn from a Literature degree, until the beginning of 2017 he worked as assistant manager in a local company run by his father; the two are now trying to open a similar company of their ownership. Matt is the co-author, and collaborates with Alex on the game setting since 2012. He is 34 years old and, with a degree in Media Studies, works as web content editor and social media marketing expert in a local firm, with a fixed term contract. Manuel is Tin Hat art director, and has similarly collaborated on the project since 2012. He is 41 years old, holds a degree in Arts, and has spent 20 years as a graphic designer in various companies either 
as self-employed or with standard fixed term positions, the last of which closed at the end of December 2016, thereby leaving him unemployed.

With such a good mix of skills, the team's common ground, besides similarities in formal education, lies in a deep knowledge of the so-called 'geek'- or, less recently, 'nerd'-subculture: that is, of anything that has to do with RpGs, comics, video-games, TV series, and, more generally, the 'pop culture', but also anything that concerns (new) technologies, (hard) sciences, and hacking. The three have known each other for many years, and role-played together - table top and live, as players and scriptwriters - in manifold occasions, collaborating within several gamers associations, attending RpG events all over Italy, and hanging around comics and games conventions for decades. ${ }^{1}$

The first Italian edition of \#UH, in black and white, was presented in 2013 at a sector convention - Lucca Comics \& Games, the world's second largest receiving a good public reception but having no luck in the quest for a financial backer. The group decided then to embark on a crowdfunding endeavour on Kickstarter, launching their campaign on April 7, 2014 and being successfully funded - the first Italian project in the considered sector - on May 15, 2014, with a final score of 243 backers who pledged $\$ 16,301$. They were thus able to cover the print and shipment costs of the second expanded Italian edition, in colours, and the translation and editing costs for the English one. In spring 2015, they were contacted by one of the main Italian distributors of the sector, who since then has been selling \#UH products with very good results. At the Lucca convention of Autumn 2015, with a stand hosted in the distributor's area, Tin Hat presented the preview of their second main product, the board game Dungeon Diggers, which was then proposed to the international public, still in its playtesting version, in October 2016, at another huge game convention in Essen, Germany, and at the 2016 edition of Lucca Comics \& Games. The board game was then at the centre of a second Kickstarter campaign, aimed at covering production and distribution costs: launched on April 1, 2017, corresponding to the Play Modena convention opening, it successfully closed on May 10, 2017 with $€ 18,249$ from 304 backers.

From an organizational and financial point of view, Tin Hat is a VATregistered non-profit association composed of three members. The members cover expenses with precedent revenues and, when needed, by contributing from their personal accounts with small amounts of money (hundreds of euros, never above 1000), that they gradually regain after sales. None of the three earns anything in terms of revenue sharing. The association account rarely reaches over 1000 euros (this generally happens when revenues are allocated to imminent planned expenses), and the financial year closes with a balanced budget. Tin Hat members run the collective autonomously and as peers. The internal division of labour is loose and underspecified, with large overlapping of competence, frequent co-working, and continuous informal mutual learning (see also Section 4). 


\subsection{Data and Methods}

The case being known to one of the authors (Chiara) for some time, she started actual ethnographic research in December 2014. Through a mix of participant observation and cyber-ethnography, she focused (a) on team meetings and 'backstage' work practices, (b) on interactions and activities during and around conventions and other events, and (c) on social media campaigning activities and online interactions. Data include field notes, audio, video, and photographic material, as well as the Kickstarter campaign, the \#UH website, and the social network pages.

Furthermore, the other two authors conducted an in-depth collective interview with the team members, in order to gain knowledge into their narrative as a team of creative, independent producers. Video interviews released to the media have been considered as well, though obviously as a different selfpresentation genre, so to speak.

\section{Collectively Constructing a Critical Product}

\#UrbanHeroes is a 'gritty, superpunk tabletop RpG about superheroes, conspiracy theories, physics and the contemporary pop culture [...] that will grant you the opportunity to play as a posthuman imbued with superpowers living in a cruel, materialistic and dystopian parallel of our own world that will challenge your beliefs and your sense of reality' (Kickstarter campaign).

The setting rests on a simple premise: in 2008, CERN's particle collider (LHC) in Geneva exploded, particles $Z$ were liberated and since then - randomly and all over the world - people started to manifest superpowers, 'or at least this is what they've been called, on the basis of a culture in which super-heroes were already present as a concept' (Alex, video-interview, 12 April 2015). How would our society react to such an event? This is the question that lies at the core of \#UH. And that is the vector of the social critique on contemporary capitalist society and its spectacle that its creators purport via an extreme realism, in both the game setting and the rules.

The critical viewpoint that \#UH conveys - visible in the game motto: RIOT NOW - relies on excess, which works as an unveiling mechanism, and is based in the mundane: \#UH is superpunk. ${ }^{2}$ Earth-Z, the planet where the game is set, perfectly matches our own world, and evolves in time with it. Scientific coherence played a crucial role in the creation of the background story, and plays an important one for the rules. From a formal and stylistic point of view, to be noticed are (a) the rough, excessive, and vulgar style that characterizes the game setting and, in apparent contrast with excess and roughness, (b) the carefully designed and well-finished nature of the creative products (and the same holds for their promotion, see section 5). In a way, both the game per se, on the one hand, and the contradictory mixture of overblown trash (game characters, stories, dialogues, etc.) and attended refinement (game rules, graphics, 
adherence to facts, etc.), on the other hand, can be regarded as détournement, as the overturning of the established relations between concepts, and of all the acquisitions of earlier critique (Thesis 206). It is not by chance that Debord assigns a fundamental role to the 'language of contradiction', in which, he claims, cultural critique emerges as unified, in that it dominates culture as a whole and is undetached from the critique of the social whole (Thesis 211).

The detournement is reflected also in the practices of creation and work that Tin Hat employs. Typically, they work jointly and in parallel at Manuel's place, called 'The Mansion', where they spend the night ${ }^{3}$ after 'the dinner of the desperate ones' (everyone brings something, otherwise take-away). Working in co-presence, first of all, allows discussing in detail new ideas as well as the manifold aspects of the creative-products-in-creation; to show each other partial, unfinished works; to try and evaluate together alternatives. Team meetings, furthermore, are characterized by playfulness, irony, self-irony and reciprocal teasing, which are the elements that build up to the creativity of the group, to the quality of its creations, and to the constant learning of its members. Working time is punctuated by facetious interludes - temporary, often only apparent suspensions of work activities - that are easily inserted in the working flow given its multi-tasking, intersecting, and overlapping organization and its fragmented rhythm. In brief, pleasure at work is constructed as a collective practice (Gherardi, Nicolini and Strati 2007; Loriol 2014), fatigue and stress are playfully managed, and all this makes reciprocal critique possible while reducing potential opportunities for conflict.

There is a further issue, that resonates intensely with what Debord called 'the fluid language of the anti-ideology', where quotations from the canonized theoretical authority are banished (Thesis 208). Facetious interludes may originate from funny anecdotes and gossiping, or the work-related necessity to check an information, look for examples, search inspiration, and so on. Such an inspiration may spring out something they regard as well-done within the geek subculture, or a scientific news, and yet mostly comes from 'the most horrific horrors' of our glocal world. The means to reach the latter is the web, alongside the Facebook group 'Tin Hat Club' (on invitation) where fans share 'horrors' such as the latest conspiracy theory, or airy-fairy political declaration. The possible objects of critique and mockery - always conducted with an ironic and rough style, also in the 'backstage' of team interaction - are innumerable. This is \#UH raw material. If it is true that the spectacle masterfully organizes the ignorance of what happens and, immediately after, the oblivion of what we anyway came to know (Debord 1978/1998), then \#UH can be seen as a counternarrative, a countergaming example, and ultimately an act of resistance.

Finally, it is worth noticing that the above described context, for team members, requires more innovative skills than those required by their 'standard', 'official' work. Albeit in different forms, each of the three finds in Tin Hat both the chance to work with quality standards that seem not allowed in the contemporary production model, too old or too frantic to be able to dwell on the details, and a recognition of their competences and interests. It is indeed their 
passion for gaming and for their professional activities that sustains the subjective conditions to engage in the (non-paid) activities of Tin Hat. Therefore, this case study shows one of the main tensions embedded in creative work, namely the fact that workers perform activities in which pleasure and obligation become blurred (Hesmondhalgh and Baker 2010). Similarly, they have to find a balance between recognition and self-identification, on the one hand, and the need to earn a living, on the other (Huws 2010). In the attempt to interpret this phenomenon, in media studies the concept of playbor was introduced (Kücklich 2005), to refer to self-expression and to the valorization of collaborative phenomena, that are however embedded into institutional and technological settings oriented toward capital accumulation (Scholtz 2012). As we are about to see, Tin Hat does not fully escape from such a (glossed over) mechanism.

\section{Digitally Setting Up an Interactive Spectacle}

Tin Hat makes intense use of social media and other digital platforms ${ }^{4}$ for promotion, advertising, and public/fandom engagement purposes. The Kickstarter campaign - planned with extreme attention and designed in detail for the aimed target - represented not only the opportunity to increase product quality (given Tin Hat financial conditions), but also equalled the capability to reach a new audience: the US, and more generally international, one.

Even before we knew Kickstarter as a solution, there was already a commitment to translate and try to make it big abroad: choosing the logo, picking up a Bansky, thought for the US and UK [...] We used Kickstarter half as a crowdfunding campaign and half like launching a company [...] According to the data, Kickstarter is the one that offers an international audience, for a project like that Kickstarter is perfect, for a super-heroes concept [...] abroad there's a history of heroes and superheroes.(Collective interview, 15 April 2015)

All in all, the Kickstarter campaign represented the first international avenue for the Tin Hat debut.On the other hand, social media like Facebook have been used both to cultivate social relations, and to foster Tin Hat's reputation as a team of critical and independent, playful and foolish game producers. Such an 'indie' identity, indeed, is staged in the interactive spectacle of posts and comments, which are informal, playful and ironic but also well-finished, both linguistically and graphically - see the following excerpt and Figures 1 and 2.

This is not bullshit for plugging: Manuel is preparing a file for customizing with a $3 \mathrm{D}$ printer YOUR personalized mask. What does this mean? Real masks in the real life, bitches! 


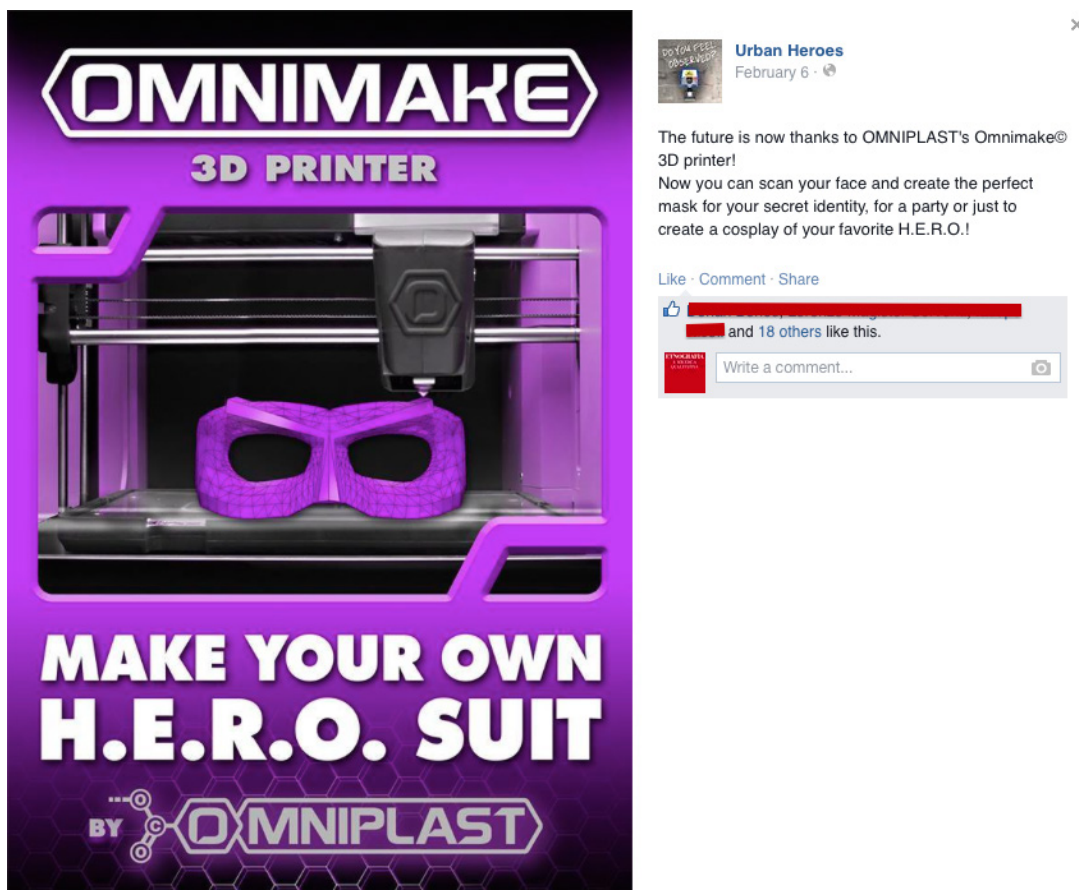

Fig. 1: A picture posted on the \#UH Facebook page, with the accompanying caption. Manuel Strali.

(The Urban Heroes team does not answer for possible violent acts / robberies / murders committed while wearing the customized masks)

(6 February 2015, 3:18 PM-translated from Italian)

Irony, moreover, is often coupled with self-irony, in a way that (strategically) builds up to the team identity (and its spectacularization).

From now until PLAY [convention], if you don't hear from us, if the posts will be less frequent, if you will see us wearing human flesh dresses and talking backwards, it will be because we are doing too many things at the same time [...] (4 March 2015, 10:56 AM)

Tin Hat identity equals that of its members. The 'characters' displayed onstage are Alex, Matt and Manuel, who even have, each, a personal logo-portrait designed by the latter (Figure 3). Such characters are not completely 'fictional', but 'based on a true story', so to speak, therefore 'authentic' (Varga 2011). There is no mystery, for instance, about the fact that they all have other 'official' jobs, ${ }^{5}$ and a more or less precarious financial condition. Further, the authenticity effect is enhanced by the more or less implicit characterization of team members as, we could say, foolish assholes, although the kind with whom one 


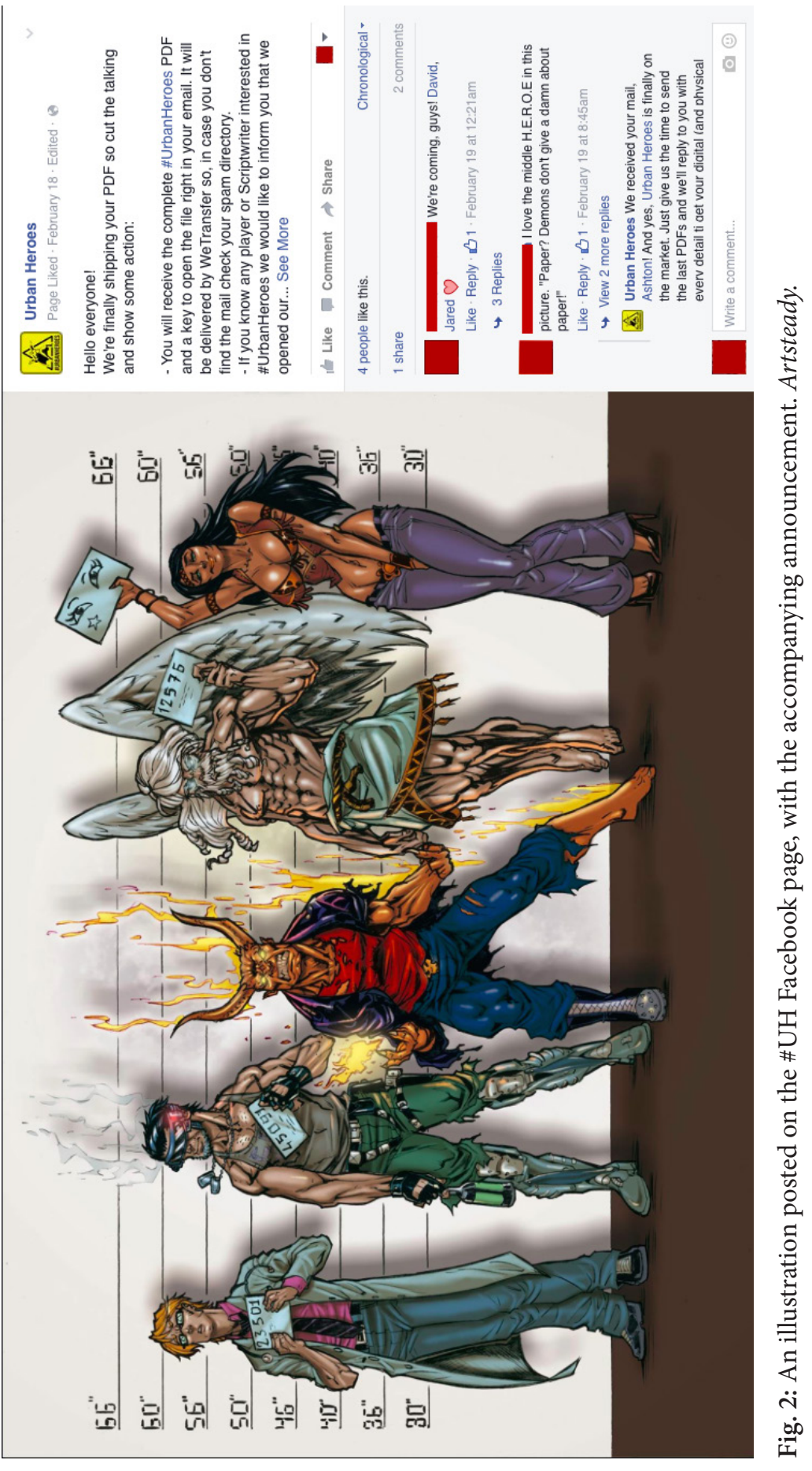



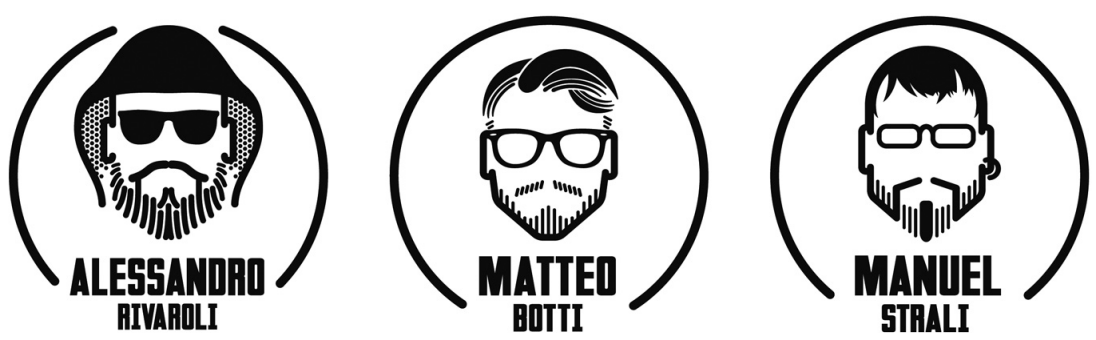

Fig. 3: Logo-portrait of Tin Hat members. Manuel Strali.

can sympathize. The fact that people's everyday life is displayed more and more in its mundane details, 'confessed' (Foucault 1980) and staged at the same time, and made the spectacle itself - 'reality emerges from the spectacle, and the spectacle is real', as Debord maintained (Thesis 8 ) - has been a very important success condition of the crowdfunding campaign and the social media one alike.

The objective of cultivating social relations, on the other hand, has been brought about not only through frequent posting and quick replying, but also and especially by creating spaces and opportunities for followers' engagement and active participation, as well as for their mutual interaction in a communitylike manner - this is where the spectacle becomes interactive. The Facebook group, for instance, is a 'place' for followers to show and share their \#UHrelated 'stuff' (e.g., the drawn portrait of a playing character), and to ask questions, comment and discuss with both the game creators and the other players. 'Expedients' aimed at fostering player-to-player interaction and a sense of community are manifold: share your playing-character sheet, post your photos of the convention (they usually represent demo-sessions, Alex or Manuel drawing at the stand, group of fans wearing an \#UH t-shirt, etc.), vote for your favourite non-playing-character, publish your sketches (there is a dedicated 'Fan Art' section on the website), and so on. Finally, what one can refer to as the fan made dimension of \#UH enters the game setting through the 'Project $Z$ ' webspace, where groups of players share detailed 'setting modules' for diverse cities as seen through the dystopic gaze of \#UH.

Alex: [...] so that we can create a description of the world done through our players playing sessions [...] Therefore, even a beginner, one who has just approached \#UrbanHeroes, and who chooses for instance to play in Manhattan, can connect and see what information are already available about Manhattan [...]

Matt: There's another interesting issue I always suffer about RpGs: when you play on Earth, and the history of our planet is involved, I always suffer the suffocating stereotypisation [...] unless you're from New York, for example, you'll always create a copy of the copy of the copy $[. .$.$] by connecting these dots you not only obtain a network of$ 
contacts, so that people who don't know each other start doing so, collaborating and maybe playing together - and therefore they enrich themselves one way or the other-but we will also have the opportunity to make use of the direct experience of a network of players, an experience that is for sure higher than our own.

(Video-interview, 12 April 2015)

By leveraging on a well-staged identity, supported by a distinctive communicative style (i.e. a specific aesthetics), Tin Hat has been able to build a community that represents a prime example, we believe, of the interactive spectacle. No doubt mutually enriching, even close social relations have emerged; no doubt people engagement has been huge and has often brought to fruitful collaboration; no doubt such a collaboration has developed through informal interaction and creative ways of doing and organizing activities. Yet such authentic relations are simultaneously staged and made part of the spectacle in order to extract value for the promotion and marketing of the 'indie' creative team and the 'indie' creative product alike (cf. Arvidsson and Colleoni 2012). Moreover, as already mentioned, the counter-narrative elaborated by this small independent gamers' association is almost completely based on the 'free work' of its members, who are required to provide by themselves a source of income and a base level of material security.

\section{Discussion and Conclusion}

In this essay we have proposed - through the presentation of a case of independent game producers - an analysis of the ambivalences that characterize producing, funding, and consuming in the age of the 'interactive spectacle'. This has brought us to criticize two main assumptions which, in our view, have not yet been debated deeply enough by the scholars studying the emergent forms of work in digital capitalism. First of all, we have shown that the analysis of 'free work' cannot be limited to the spaces of opportunities and satisfaction that it opens for knowledge and digital workers, since subjects experience complex dynamics of valorization of their own lives, and therefore of their own desires and passions. Secondly, we have critically re-read the approaches that consider - in the specific case of game producers - the use of instruments as crowdfunding and social media as a way of production that should also automatically build communities, through horizontalized patterns of communication.

By leveraging on Debord's concepts, we have thus tried to thematize, in the era of the knowledge society and of informational capitalism, the 'degradation of being into having' - produced first and foremost by the valorization of the subjects' existence - and the 'sliding of having into appearing' - produced through the interactive media technologies in the society of the spectacle, in its 2.0 version. The Tin Hat case well exemplifies the whole transition being-having-appearing, not only because its members' longstanding passions are now a constitutive part 
of their work, but also for the strong intertwinement of 'real' and 'fictional' life. The 'real' Tin Hat characters often work together in the house of one of them, and their 'fictional' characters, those with a logo-portrait who interact with the fans' community through the social media, are in fact 'authentic' and close to the 'real' characters.

Furthermore, we have highlighted how subjects at the same time display strategies to re-appropriate their own subjectivity and to criticize the dominant model of production and consumption, through the use of new media. Such re-appropriation is enacted, in the case of Tin Hat, through a Debordian détournement, both of the existing culture and of the existing social relations. Concerning culture, Tin Hat operates a détournement by bringing a dystopian social life into the \#UrbanHeros game, which gives its own representation of social reality, whereas the current culture of gamification goes exactly in the opposite direction, that is, bringing the game into the social life and in particular into the working life, with the aim of using entertainment to enhance productivity. Finally, concerning social relations, the détournement happens in the interactive spectacle of the social media, where relations are in this context supposed to be instrumental to the assessment of the reputation of Tin Hat, but they become also mutually enriching and engaging, and create a sense of community.

The construction of social relations in countergaming practices is, indeed, the wealth through which Tin Hat sustains its existence as an independent organization collaboratively managed, even financially, for example through crowdfunding. From this perspective, the established relations, and the construction of new ones, are necessary means of survival in Tin Hat's experience, and they are cultivated and valued through the re-appropriation of capitalist digital platforms. The practices oriented to the construction of social relations, through the Facebook page or the Kickstarter campaign, are indeed what found the connection between the cooperative practices of Tin Hat and the interactive spectacle, as in these practices the subjectivities of Tin Hat members are both the subjects and objects of spectacolarization, through the mediation of contemporary digital platform. In conclusion, social relations themselves become, irremediably, part of the interactive spectacle, that can be read as based, on one side, on mechanisms that extract value from the 'free' and self-valourizing practices of individuals, and, on the other, on the instruments - in this case crowdfunding platforms - that encourage people to engage in risky actions while leaving them alone in managing the implications of a possible public failure. The interactive spectacle, therefore, appears - in the analysed case study - as a necessary passage point for contemporary collaborative practices of production, and this holds notwithstanding and almost independently of the critical stances, like countergaming, brought forward by such practices. Tin Hat is then an interesting case to analyse how the tactic of détournement can be used in a role-playing game and in the practices of its creation. However, how the passion and the creativity of an independent association can escape the exploitation embedded in the precarious forms of (digital) labour, still needs to be disentangled. 


\section{Acknowledgement}

We are very grateful to the members of Tin Hat Games for allowing us to enter their world. We also wish to thank all the people - players, fans, artists, translators, journalists, etc. etc. - with whom Tin Hat interacted and who allowed for the ethnographer to attend, and often to record, such interactions.

\section{Notes}

1 'What associates us all is the passion for role-play games [...] we have accumulated a certain knowledge of the commodities sector [...] we know the milieu very well.'(Collective interview, 15 April 2015)

2 The superpunk surpasses punk individualistic nihilism, and is grounded in displacement intended as an aesthetics that points towards everyday life and mundane social phenomena.

${ }^{3}$ Once a week, in business-as-usual times, or several days in a raw (5 to 8 on average) before convention premieres and the like.

4 They have a website with embedded blog for \#UH, a page and a group on Facebook for \#UH, a page for Tin Hat Games and a 'Tin Hat Club' closed group, accounts on Twitter, Instagram and Google+, and a space on Issuu where they share various game-related free material.

${ }^{5}$ Notice that the presence itself of something labelled 'official' calls to mind something else that is 'unofficial', 'off-the-records', hence (more) authentic.

\section{References}

Armano, Emiliana and Annalisa Murgia. 2015. 'The Precariousnesses of Young Knowledge Workers. A Subjectoriented Approach' In Precariat: Labour, Work and Politics, ed. Matthew Johnson, 102-117. New York: Routledge.

Armano, Emiliana, Annalisa Murgia and Maurizio Teli (eds.) 2017. Platform Capitalism e confini del lavoro negli spazi digitali. Milano: Mimesis.

Arvidsson, Adam and Elanor Colleoni. 2012. 'Value in Informational Capitalism and on the Internet'. The Information Society 28 (3): 135-150.

Arvidsson, Adam and Nicolai Pietersen. 2013. The Ethical Economy: Rebuilding Value After the Crisis. New York: Columbia University Press.

Ballatore, Magali, Maria Del Rio Carral and Annalisa Murgia (eds.). 2014. Special Issue 'Quand 'passion' du métier et précarité se rencontrent dans les professions du savoir'. Recherches Sociologiques et Anthropologiques 45 (2).

Best, Steven and Douglas Kellner. 1999. 'Debord and the Postmodern Turn: New Stages of the Spectacle', Substance 90: 129-156.

Beverungen, Armin, Birke Otto, Sverre Spoelstra and Kate Kenny, eds. 2013. Special Issue 'Free Work'. Ephemera, Theory \& Politics in Organization 13 (1). 
Boltanski, Luc and Eve Chiapello. 1999. Le nouvel esprit du capitalisme. Paris: Gallimard.

Chicchi, Federico, Elisabetta Risi, Eran Fisher and Emiliana Armano, eds. 2014. Special Issue 'Free and unpaid work, gratuity, collaborative activity and precariousness. Processes of subjectivity in the age of digital production'. Sociologia del lavoro 133.

Debord, Guy. 1967/1994. The Society of the Spectacle (translation by Donald Nicholson-Smith). New York: Zone Books.

Debord, Guy. 1978/1998. In girum imus nocte et consumimur igni (translation by Donata Feroldi). Milano: Mondadori.

Foucault, Michel. 1980. The History of Sexuality: Volume I: An Introduction. New York: Vintage Books.

Fuchs, Christian. 2014. Digital Labour and Karl Marx. New York: Routledge.

Galloway, Alexander. 2006. Gaming: Essays on Algorithmic Culture. Minneapolis: University of Minnesota Press.

Gherardi, Silvia, Davide Nicolini and Antonio Strati. 2007. Special Issue 'The Passion for Knowing. Organization 14 (3).

Harvey, David. 2014. Seventeen Contradictions and the End of Capitalism. Oxford: Oxford University Press.

Hearn, Alison. 2010. 'Structuring Feeling: Web 2.0, Online Ranking and Rating, and the Digital 'Reputation' Economy'. Ephemera, Theory \& Politics in Organization 10: 421-438.

Hesmondhalgh, David and Sarah Baker. 2010. 'A very Complicated Version of Freedom: Conditions and Experiences of Creative Labour in Three Cultural Industries'. Poetics 38 (1): 4-20.

Huws, Ursula. 2010. 'Expression and Expropriation: The Dialectics of Autonomy and Control in Creative Labour'. Ephemera: Theory \& Politics in Organization 10 (3-4): 504-521.

Jagoda, Patrick. 2013. 'Gamification and Other Forms of Play'. Boundary 240 (2): 113-144.

Kücklich, Julian. 2005. 'Precarious playbour: modders and the digital games industry'. fibreculture 5: http://five.fibreculturejournal.org/fcj-025-precarious-playbourmodders-and-the-digital-games-industry.

Loriol, Marc. 2014. 'Le plaisir au travail, une construction collective'. Soins 59 (790): 36-38.

Scholz, Trebor. 2012. Digital Labor: The Internet as Playground and Factory. New York: Routledge.

Scholz, Trebor. 2016. 'Platform Cooperativism Challenging the Corporate Sharing Economy’. Rosa Luxembourg Stiftung New York Office 26.

Srnicek, N. 2016. Platform Capitalism. Cambridge: Polity Press.

Van Dijck, José. 2013. The Culture of Connectivity: A Critical History of Social Media. Oxford: Oxford University Press.

Varga, Somogy. 2011. Authenticity as an Ethical Ideal. New York: Routledge. 
